\title{
"Recrear, instruir e advogar os interesses suburbanos": posicionamentos sobre o futebol na Gazeta Suburbana e no Bangú-Jornal (1918-1920)
}

\author{
Nei Jorge Santos Junior \\ Victor Andrade Melo ${ }^{* *}$
}

\begin{abstract}
Resumo: Esse estudo tem por objetivo discutir os posicionamentos sobre o futebol veiculados em dois periódicos do subúrbio do Rio de Janeiro: a Gazeta Suburbana e o BangúJornal. Estabeleceu-se como recorte temporal os anos de 1918-1920 por ter sido um momento em que cresceu a tensão no campo do futebol carioca, notadamente devido ao maior trânsito de jogadores entre os clubes de duas importantes ligas: a Suburbana e a Metropolitana. Partimos do princípio de que essa investigação pode ampliar nosso olhar sobre o esporte por prospectar o ponto de vista de quem defendia os interesses de uma região periférica da cidade.
\end{abstract}

Palavras-chave: Futebol. História do Esporte. Imprensa.

\section{INTRODUÇÃo}

A presença do esporte na imprensa fluminense é perceptível desde a transição das décadas de 1840/1850. Já no Jornal do Commercio, um dos mais importantes do período imperial, era comum o veicular de informações sobre o turfe e o remo, as modalidades que pioneiramente se estruturaram no Brasil. No decorrer do século XIX, se estabeleceu um relacionamento de mão dupla entre os clubes esportivos e os periódicos. Para os primeiros, os jornais e revistas eram fundamentais para a divulgação de suas iniciativas, bem como para a conformação de uma boa imagem da prática. Para os segundos,

\footnotetext{
"Doutorando, Estudos do Lazer, Universidade Federal de Minas Gerais, Belo Horizonte, MG., Brasil. E-mail: edfnei@hotmail.com

"Professor, Faculdade de Educação, Universidade Federal do Rio de Janeiro, Rio de Janeiro, RJ, Brasil. E-mail: victor.a.melo@uol.com.br
} 
tal relação era uma forma de se vincular ao que havia de up to date na sociedade, uma novidade que se ligava à ideia de progresso e "civilização" (MELO, 2012).

Além disso, com o decorrer do tempo, conforme o esporte se tornou um tema socialmente mais valorizado, a veiculação de notícias a seu respeito ajudava a potencializar os lucros das empresas jornalísticas, tanto mais quando a população passou a progressivamente consumir produtos ligados à manifestação (MELO, 2012).

Em função dessa intensa relação, a imprensa é uma relevante fonte para a investigação das tensões que cercaram a conformação do campo esportivo. Mais do que entendê-la enquanto fórum que repercutia determinadas compreensões sobre a prática, é preciso também considerá-la, inclusive por intermediar interesses diversos, como agente que influenciou na consolidação do fenômeno.

A maior parte dos periódicos privilegiava um ponto de vista mais afeito aos interesses das elites, mesmo que, por vezes, a partir de um olhar crítico. Ainda que com esse viés, nos jornais e revistas, "em função da sua ambiguidade, típica de sua função mediadora, é possível captar diferentes e divergentes perspectivas sobre a prática, cuja conformação ajuda-nos a entender o quadro de uma sociedade em mudança" (MELO, 2012, p. 47).

De toda forma, seria interessante diversificar esse olhar, não só para prospectar outros posicionamentos sobre a prática, como também para que se perceba a diversidade de influências no delineamento do campo esportivo. Nesse sentido, trabalhar com periódicos de natureza diferenciada pode ser uma possibilidade de ampliar nossa perspectiva sobre o tema. Esse é o caso dos jornais que circulavam de forma mais restrita e numa região periférica da cidade do Rio de Janeiro, a chamada imprensa suburbana.

Ainiciativa de produzir um jornal que tinha por objetivo "recrear, instruir e advogar os interesses suburbanos"(COM licença, 1883, p. 1) é uma expressão do desejo de alguns indivíduos, residentes em bairros distantes daqueles onde habitavam as elites, de se engajarem 
na luta por melhores condições de vida, trabalho e lazer. Essa intenção, presente na maioria dos periódicos editados na região, era comum entre alguns líderes que se dedicavam "de corpo e alma à causa da melhoria da qualidade de vida dos subúrbios" "(COM licença, 1883, p. 1), denunciando a omissão do poder público frente ao cenário de abandono das áreas mais distantes do Centro ${ }^{1}$.

Mesmo conscientes das dificuldades em lograr êxito em suas reivindicações, os editores e cronistas desses periódicos, normalmente moradores da região, vislumbravam, por meio de seus escritos, estimular as mais diferentes formas de reação da população local frente ao descaso das instituições públicas. Eles usavam suas modestas publicações como instrumentos para se fazer ver e ouvir na cidade que rapidamente crescia (MENDONÇA, 2011).

A maneira como esse esforço foi entabulado e a forma como foram apresentadas as soluções para os problemas levantados nos permitem perceber algo da multiplicidade de experiências dos moradores do subúrbio. De fato, esses jornais são conformados, mas também ajudam a conformar uma experiência suburbana.

Não sendo o subúrbio, todavia, um local monolítico, unidimensional ou homogêneo, não surpreende que mesmo entre jornais com objetivos aproximados seja possível identificar diferenças significativas nas percepções sobre a sociedade da época. Essas peculiaridades têm relação com o público para o qual se dirigiam, que poderia ser de toda a zona suburbana (um conceito sempre muito impreciso) ou de um bairro específico, bem como com os conteúdos que se considerava de interesse para a população.

Nos esportes, notadamente no futebol, alguns desses periódicos enxergaram um importante objeto para a construção de elos de sociabilidade, além de atrativo de interesse do potencial público comprador. Por isso, com regularidade noticiavam os resultados dos jogos dos campeonatos e a programação dos clubes locais, principalmente daqueles que disputavam a Liga Suburbana.

${ }^{1}$ No estudo de Mendonça (2011), é possível perceber um panorama da atuação desses periódicos suburbanos. Ver também, Abreu (1987). 
Fundada "por um grupo de distinctos sportmen" (FOOTBALL..., 1907, p. 4), em abril de 1907, a Liga Suburbana de Futebol congregava os clubes que não conseguiram arcar com os custos para filiar-se à Liga Metropolitana, tais como o Mangueira, o Nacional, o Riachuelo, o Sampaio, o Pedregulho, entre outros, todos sediados nos subúrbios do Rio de Janeiro.

Já a Liga Metropolitana fora fundada, em julho de 1905, por representantes do América, do Bangu, do Botafogo, do Fluminense e do Foot-Ball and Athletic Club. Foi a pioneira entidade organizativa do futebol no Rio de Janeiro, promovendo os primeiros campeonatos da cidade. Era uma associação mais elitista, que demandava dos candidatos à filiação altas despesas.

Alguns anos depois, todavia, a Liga Metropolitana criou a $2^{\mathrm{a}} \mathrm{e}$ a $3^{\text {a }}$ divisão, buscando aumentar o número de filiados e atrair os principais clubes da Liga Suburbana, que com isso se fragiliza, somente voltando a atuar de forma mais efetiva em 1916, motivada por um periódico, a Gazeta Suburbana.

Como podemos ver, na segunda metade da década de 1900, o futebol já se apresentava como um importante elemento na construção de laços de identidade. Conforme o esporte foi se espraiando pela cidade, cresceram os conflitos simbólicos ao seu redor, algo que era fomentado pelos periódicos.

A grande imprensa, aquela de maior circulação na cidade (Correio da Manhã, O Imparcial, Gazeta de Notícias, O Paiz, entre outros), comumente considerava as equipes do subúrbio e seus torcedores como impertinentes e mal educados, responsáveis pelo número crescente de tumultos que havia nos campos. Por exemplo, nas palavras de Mario Pollo (1916, p. 9), cronista do Correio da Manhã, essas agremiações seriam responsáveis por afastar dos estádios as "boas famílias cariocas", cansadas da situação "absolutamente incômoda e desagradável" gerada pela violência da qual seriam as principais responsáveis. Em linhas gerais, mesmo que não assumidamente, defendiam os interesses da Liga Metropolitana (SANTOS JUNIOR, 2012; SANTOS JUNIOR, MELO, 2013). 
Qual terá sido a abordagem dos periódicos suburbanos sobre as tensões que existiam no meio futebolístico do Rio de Janeiro? Considerando seus interesses e objetivos específicos, como teriam reagido frente às posições da grande imprensa? Tendo em conta essas questões, esse estudo tem por objetivo discutir os posicionamentos sobre o futebol veiculados em dois importantes jornais do subúrbio carioca: a Gazeta Suburbana e o Bangú-Jornal.

Estabeleceu-se como recorte temporal os anos de 1918 e 1920 por ter sido um momento em que cresceu a tensão no campo futebolístico do Rio de Janeiro, notadamente devido a um maior trânsito de jogadores entre os clubes das ligas Suburbana e Metropolitana, fato que desencadeou críticas generalizadas (PEREIRA, 2000; SANTOS JUNIOR, 2012).

Para analisar e interpretar os posicionamentos da imprensa, tivemos em conta as sugestões de Luca (2005) e Melo et al. (2013). Prospectamos os jornais a partir de sua materialidade, intencionalidade e público almejado, sempre tratando as posições não como expressão da verdade, mas sim um ponto de vista específico, direcionado e possível sobre o tema a ser investigado.

A "Gazeta Suburbana: folha recreativa, noticiosa e de interesses gerais" foi um dos periódicos mais atentos aos problemas dos subúrbios do Rio de Janeiro. Criada em 1883, anunciava como objetivo a luta pelos interesses da região, pretendendo ser "instrumento de protesto dos moradores à falta de atenção das autoridades aos problemas que afligiam aquela sociedade e que eram comuns a outros bairros mais distantes do centro da cidade"(COM licença, 1883, p. 1).

Em sua primeira fase, o periódico não teve grande duração, seu último número foi lançado em fevereiro de 1885 . Somente em setembro de 1910, a Gazeta foi relançada, com outro grupo de editores à frente, desta vez com o subtítulo: "semanário crítico, literário, noticioso, dedicado aos interesses da zona suburbana". O jornal assumia o compromisso de, como o anterior, "trabalhar pelos subúrbios"(NOSSO..., 1910, p. 1), com o intuito de conseguir para o local "os melhoramentos e as reformas necessárias". 
A seção "Queixas e Reclamações" era o principal espaço de críticas à situação do subúrbio. No entanto, nas páginas do jornal também se divulgava a vida social. A seção "Vida Sportiva" noticiava os resultados dos jogos e as atividades das agremiações da região. Seus redatores e cronistas comumente contestavam o discurso de refinamento e fidalguia construído pelos sportsmen da Zona Sul (onde viviam as elites), distanciando-se das representações dos grandes periódicos da época, reagindo às tentativas de estigmatização.

Os cronistas da Gazeta Suburbana, além de exaltarem o desempenho e as conquistas dos clubes da região, denunciavam o aliciamento dos jogadores locais, o que, segundo o periódico, seria a prova de que o melhor futebol da cidade não se jogava nos campos da Zona Sul; tanto assim o era que as agremiações da elite tentavam a todo custo comprar os craques do subúrbio.

Com uma abordagem ainda mais local, o Bangú-Jornal, em sua seção "Vida Sportiva", também denunciava os estigmas e arbitrariedades que envolviam as agremiações da zona suburbana, destacando tudo o que se relacionava ao clube do bairro que era ligado à Liga Metropolitana, o Bangu Athletic Club.

Fundado em julho de 1918, o jornal assim informou seu intuito no seu primeiro número: "defender os interesses locais, com sinceridade sem paixão de espécie alguma"(VIDA..., 1918a, p. 3). Os editores assumiam o compromisso de "reflectir com imparcialidade, todas as manifestações do seu grande publico", tornando o periódico um "legítimo representante ante as administrações publicas" (VIDA..., 1918a, p. 3).

Produzir um jornal nos subúrbios da cidade era uma verdadeira "missão". A dificuldade de conseguir recursos era constante. Além disso, a concorrência com outros órgãos da imprensa tornava a tarefa mais árdua. As grandes empresas jornalísticas ampliavam seu mercado, tornando-se quase impossível a sobrevivência dos periódicos suburbanos por um longo tempo.

Mesmo assim, podemos dizer que essas experiências ajudamnos a entender um momento histórico marcado por uma ampliação 
considerável do lugar social e espacial da imprensa na cidade. Os posicionamentos nesse cenário veiculados podem ser de grande utilidade para captarmos outras perspectivas de encarar os problemas metropolitanos, entre as quais aqueles que cercavam o velho esporte bretão.

\section{Futebol SUbuRBano: UM CELEIRO de CRAQUES}

Na primeira semana de abril de 1919, a Gazeta Suburbana publicou uma série de matérias sobre os problemas que atormentavam os clubes da região. Entre eles, destacou a formação de um mercado de jogadores de futebol, para o jornalista uma situação preocupante que atingia diretamente as agremiações locais.

Para o cronista, essa seria a explicação para o movimento de contratações de jogadores do subúrbio: "só tem bom jogo na Liga Suburbana, pois, entre o pessoal da Metro, não anda..." (DIZEM..., 1919, p. 3). Essa constatação, a despeito dos exageros típicos de um exercício de autoafirmação, refletia aquilo que na prática malograria a ideia de distinção social tão desejada pelos sportsmen dos clubes da Zona Sul. Fosse nos pátios das fábricas ou nos modestos campos espalhados pela região, o futebol ganhava cada vezes mais espaço nos arrabaldes da cidade, praticado em mais de 200 agremiações, divididas em seis ligas ${ }^{2}$. Nesses espaços, homens dos mais diversos perfis, participando de jogos e campeonatos cada vez mais disputados, progressivamente ganhavam destaque por sua habilidade com a bola nos pés.

Eram os players das camadas menos abastadas praticando um esporte de origem inglesa que já adquiria feições cariocas: futebol de brancos e negros, nacionais e imigrantes, analfabetos e letrados, um mosaico de gente envergando uniformes que coloriam a cidade,

\footnotetext{
2De acordo com Malaia (2010), durante a década de 1910 e boa parte da década de 1920, havia pelo menos seis ligas reunindo os times da região: a Liga Sportiva Suburbana, ou "a Suburbana", (com cerca de 25 clubes inscritos), a Associação Athletica Suburbana (com cerca de 20 clubes), a Aliança Sportiva Municipal (sempre com mais de 10 clubes), a Liga Rodrigo de Freitas (que não ultrapassava os 10 clubes), a Liga Sportiva de Futebol (com cerca de 10 clubes) e a Associação Brasileira de Sports Terrestres (que raramente chegava a 10 clubes).
} 
explicitando sua diversidade. Eis o cenário onde as agremiações da elite começaram a buscar jogadores para completar seus quadros.

O maior trânsito de jogadores estava relacionado não somente a um alargamento simbólico dos sentidos do jogo. Sobretudo era uma expressão de uma nova dinâmica econômica, que induzia a uma maior valorização dos resultados. Com isso, a menosprezada Liga Suburbana se transformava num atrativo dado que era considerada um "celeiro" de bons futebolistas.

Em função dessa tendência, em 1917, a Liga Metropolitana reformulara seus estatutos e criara um código para restringir as transferências de jogadores. O intuito era manter um caráter elitista, no mínimo exercer um forte controle sobre a prática. Num primeiro momento dificultou-se a troca entre agremiações filiadas à entidade. Posteriormente, isso também foi feito no que tange ao trânsito entre ligas. Previa-se que: "Nenhum jogador poderá disputar jogos de campeonato ou de torneios por outro club sem que tenha decorrido o estagio de um anno a contar da data do último jogo do gênero de desporto em que tenha tomado parte" (ESTATUTOS..., 1917, p. 13577). Era a chamada "Lei do Estágio".

Alguns clubes da Liga Metropolitana, contudo, logo burlaram a regra, notadamente para contratar jogadores das equipes suburbanas. A fórmula era simples. Aos que se destacavam nos campos era oferecido dinheiro ou um bom emprego, por vezes os dois, para que se transferissem. Os que aceitavam eram incluídos no quadro de sócios da nova agremiação. Com uma dupla filiação, o jogador tinha o prazo de trinta dias para optar por quem atuaria (escolhendo obviamente o novo time).

Como se pode perceber, isso também era proibido, mas como se tratava de uma dubiedade regulamentar, contava-se sempre com o trânsito de influências e a complacência da direção da Liga Metropolitana. Por vezes, era negado o registro, mas em geral a estratégia lograva êxito.

Rapidamente a grande imprensa reagiu a essas ocorrências. Alguns questionaram a validade de tanta regulamentação para a 
defesa do amadorismo, mas a maioria criticou mesmo o oportunismo daqueles que enxergavam no futebol uma forma de ganhar um bom salário. Como destacou o cronista de O Imparcial:

Para os sportsmen que entendem que a entidade suburbana não preenche os fins progressivos do desenvolvimento sportivo da nossa terra, como de quando em vez se propala nas rodas desportivas, levamos ao conhecimento daquelles que de facto se interessam pelo progresso do football, o escandaloso caso de suborno, de vantajosas promessas de bons empregos, de gordas gorjetas que estão sendo postas em prática aos jogadores da Suburbana para se filiarem aos diversos clubes das três divisões da Metro. [...]

E depois digam que a Suburbana não é o celeiro da Metropolitana (A SUBURBANA... 1919, p. 9).

As contestações e limitações não foram suficientes para impedir o trânsito de jogadores. Somente durante a temporada de 1919, a Liga Metropolitana aprovou aproximadamente 45 transferências, inclusive para equipes da $2^{a}$ divisão, como foi o caso do Mangueira e do Carioca, que adquiriram juntos nove futebolistas oriundos de agremiações suburbanas (SANTOS JUNIOR, 2012). Pela imprensa, acirraram-se as críticas por parte tanto dos defensores da manutenção de uma visão mais elitista do esporte quanto dos que pugnavam pelos princípios do subúrbio.

Os periódicos publicados nos arrabaldes da cidade rapidamente se mobilizaram. A Gazeta Suburbana passou a, de forma contundente, denunciar o desmonte das equipes da região:

\section{DIZEM...}

que o Vasco pretende comprar oEngenho de Dentro. que o Sr. Almeida Marques vae nomear uma comissão para appreender os "caçadores de players" suburbanos (OS QUE desertam..., 1919, p. 3).

O jornal exigia providências da direção da Liga Suburbana, compreendendo que a manutenção desses jogadores seria de suma importância para a sobrevivência do campeonato pela entidade 
promovido. Para o periódico, aliás, defender os clubes locais não era uma ação relacionada apenas ao futebol. Ia mais além, envolvendo diretamente a pugna pelos interesses do subúrbio; a divulgação, manutenção e valorização de hábitos e princípios da região.

A missão, contudo, era complicada, e não somente por causa dos clubes mais tradicionais. A ascensão do Vasco da Gama, por exemplo, dificultava a resistência suburbana: os comerciantes portugueses estavam dispostos a fazer da agremiação um dos grandes empreendimentos da colônia no Rio de Janeiro e não fizeram "muita questão de ter jogadores identificados com os players dos grandes clubes aristocratas" (MALAIA, 2010, p. 136).

O clube cruzmaltino assumiu, sem se importar com a cor da pele ou com a posição social dos jogadores, a postura de se preocupar apenas com a vitória. Seus dirigentes contrataram, de uma só vez, seis jogadores das duas melhores equipes da zona arrabaldina da cidade. No Engenho de Dentro, equipe tricampeã da Liga Suburbana, foram buscar Nelson da Conceição (conhecido como Chauffer ${ }^{3}$ ), Alberto Quintanilha, Aquiles Pederneiras e Aristides Baptista (chamado de Esquerdinha). Também foram aliciados dois dos melhores players da Fábrica Mavilles: o defensor Lamego e o atacante Leão.

Ao entrar em campo pelo "Torneio Initium" de 1919, a equipe da cruz de malta despertou a atenção dos cronistas da Gazeta Suburbana. Surpreso com a escalação de um team com a presença de "vários elementos do Engenho de Dentro", dentre eles os principais responsáveis pelo tricampeonato suburbano, o jornalista questionou: "mas será mesmo possível que esses players abandonem seu glorioso club para jogar por um club estranho a elles, como o Vasco?" Espantado, o mesmo responde, "não queremos crer, mas... em todo caso... esperemos os acontecimentos" (OS QUE desertam..., 1919, p. 3).

\footnotetext{
${ }^{3}$ Sobre esse jogador, o estudo de Santana (2013) ajuda a melhor entender os conflitos que cercaram a transferência de futebolistas naquela ocasião.
} 
Para o jornalista, que entendia que o futebol poderia ser um importante fator de identificação e valorização do subúrbio, parecia inacreditável que interesses financeiros fossem determinantes na decisão de jogadores que, no seu entendimento, por representarem a região, não deveriam abandonar a causa de defendê-la.

Nesta mesma edição, na seção "Pelo sem fio", tratava-se com ironia o caso, criando um possível diálogo entre o jogador Mascate, que havia permanecido no Engenho de Dentro, e Chauffer, Pederneiras e Quintanilha, que deixaram o clube:

Quintanilha,

Isso não é sério, isso não se faz. Has de ter remorso e então quando voltares... a porta está fechada![assinado] Mascate.

Mascate,

Não continuo jogando no teu team por que agora vou ser profissional.

[assinado] Quintanilha.

Mascate,

Queres jogar pelo Vasco? Se quizeres escreva-me para a sede do club, faço a tua inscripção, virás a todos os treinos, terás emprego, medalha de ouro e serás campeão no próximo campeonato. [assinado] Pederneiras.

Chauffer [Nelson da Conceição],

Toma cuidado, roda. Teu pneumático esquerdo está furado e o volante não gyra... [assinado] Mascate (PELO..., 1919, p. 3).

Na mesma seção, publicou-se uma carta assinada pelo "leitor M. P. A.", na qual pedia medidas urgentes à diretoria do Engenho de Dentro para que Pederneiras não carregasse "todos para o Vasco", responsabilizando o jogador pelas "cavações" do clube cruzmaltino. Para o autor, o futebolista deveria se envergonhar por "seduzir os players" do Engenho de Dentro, "promettendo naturalmente o que não tem competencia para dar, e, embora tenha, não deixa por isso 
de ser evidente o seu papel" (PELO..., 1919, p. 3). Mais um julgava absurdo que interesses financeiros interferissem no jogo.

Essa discussão se estendeu por vários dias. Na semana seguinte, possíveis valores das contratações foram publicados na tentativa de revelar o montante a ser dividido entre os jogadores que Pederneiras levou para o Vasco. Ainda que as quantias não correspondessem a algo possível, são pistas de como a questão do mercado incomodava não só às elites da Zona Sul, mas também às lideranças do subúrbio.

Vale destacar que, mesmo com essa "fuga de pés", a prática nos arrabaldes da cidade permanecia pujante. A imprensa do subúrbio, sempre que possível, destacava as conquistas dos clubes locais. Isso alimentava ainda mais o mercado. Atenta a essas transformações, a Gazeta Suburbana seguiu se dedicando a acompanhar as transferências de jogadores, sempre criticando as transações que envolviam os oriundos da região.

Essas ações, contudo, seriam mesmo em vão. A permanência desses futebolistas nas equipes do subúrbio tornava-se difícil diante de uma nova condição: o trabalhador-jogador de futebol; homens pobres que buscavam a oportunidade de um emprego formal e passavam a enxergar no esporte a possibilidade de uma ascensão financeira.

\section{ETHOS SUBURBANO: UM OLHAR LOCAL}

O segundo domingo de julho de 1918 foi de revolta nos arrabaldes da cidade. Após longas horas de reunião, a direção da Liga Metropolitana tomou uma decisão polêmica: suspender os jogos no estádio do Bangu Atlético Clube.

A interdição, de acordo com a nota emitida pela entidade, fora motivada pelos constantes casos de violência nos jogos do clube. Para o cronista do Bangú-Jornal, tratava-se de uma decisão claramente "arbitrária". Indignado com a medida, o responsável pela seção "Vida Sportiva" expressou enfaticamente sua insatisfação nas 
páginas do periódico, questionando as possíveis razões e especulando os desdobramentos da suspensão:

Vae ter um desfecho deveras desastroso para a Liga Metropolitana, a interessante questão que se prende a injusta medida pela qual foi o campo do nosso valoroso club arbitrariamente interditado, causando esse facto enormes prejuízos materiais, além da afronta recebida em relatório apaixonado pelos dignos membros da directoria do club (VIDA..., 1918a, p. 3).

A notícia da interdição foi recebida com indignação e apreensão pelos sócios da agremiação ${ }^{4}$. O tema foi tratado em várias reuniões da diretoria do clube, que buscava soluções para o problema ${ }^{5}$ A imprensa local aguardava uma reação convicta por parte dos dirigentes. O que estava em jogo, para muitos, era a honra do subúrbio.

De fato, não fora uma decisão totalmente extemporânea. Vários ofícios, criticando as constantes ocorrências de violência nos jogos do Bangu, foram antes enviados aos representantes da equipe arrabaldina. De toda forma, os cronistas locais não se conformavam e esperavam uma medida mais drástica: "ao que sabemos, as responsabilidades da Liga já se acham bem apuradas no judiciário e em breve será proposta uma acção contra a mesma pedindo uma forte indenização por perdas e dannos" (VIDA..., 1918a, p. 3).

Mover uma ação na justiça seria, nas palavras do cronista, "uma boa e bastante aproveitável licção para os despeitos da Liga e uma estupenda victoria moral para o nosso querido club" (VIDA..., 1918a, p. 3). Tal postura era encarada como uma demonstração de que o subúrbio deveria ser respeitado.

Frente à notícia de que o Bangu entraria na justiça, o Correio da Manhã não deixou de comentar a "petulante ousadia de perturbar a doce paz dos nossos amigos da Liga Metropolitana"(A REUNIÃO..., 1918, p. 5). Já A Época informou (e ameaçou) que:

${ }^{4}$ Livro de atas das sessões da diretoria do Bangu Atlético Clube, 12 de junho de 1918.

${ }^{5}$ Livro de atas das sessões da diretoria do Bangu Atlético Clube, 25 de junho de 1918. 
o representante do Bangú desmentiu categoricamente que seu club pretendesse chamar a juízo a L.M.D.T, para ser indenizado pelas perdas a dannos decorrentes da interdição do campo da mesma sociedade. Ainda bem...(O TÓPICO..., 1918, p. 9).

Em resposta, o Bangú-Jornal provoca: "decididamente, nem bem viu a luz do dia, e já está em foco o nosso modesto semanário" (VIDA..., 1918b, p. 3). Em relação à versão noticiada pelo jornal A Época, o cronista retruca: "os leitores bem conhecem o valor significativo das 'reticências' que sempre envolvem dúvida, ironia, malicia... etc" (VIDA..., 1918b, p. 3). Reiterando o ponto de vista do jornal, reafirma que o clube estava sendo perseguido e esclarece dois pontos que a seu ver mereciam atenção:

a) Pelos processos regulares e perante autoridades competentes, depuseram pessoas qualificadas para se apurar as responsabilidades do referee que presidiu o jogo e que apresentou à Liga o relatório que deu causa à interdição do campo.

b) Chamado o referee a depor, defendeu-se, negando

o facto principal: Logo... atirou "com as responsabilidades" para a Liga rendendo uma sincera homenagem; o nosso illustre contradictor será capaz de negar, ou por outra, de desmentir o exposto?

Não cremos, mas si for, falaremos mais claro ainda... (VIDA..., 1918b, p. 3).

Com um tom irônico, o cronista reforça a cobrança e questiona a atuação tímida da diretoria do Bangu. Para ele, "o nosso valoroso club local" não poderia se orgulhar se:

n'um gesto digno e nobre e tendo um presidente honrado (todo feito de paz e amor) sujeitar-se a todos os prejuízos sofridos, conformando-se apenas com a desaffronta que sua altiva directoria conseguiu em processo regular, e desistindo de chamar a Liga às contas (VIDA..., 1918b, p. 3).

O periódico local exaltava e defendia, mas também cobrava. Recuar, ao ver do cronista, não dignificava os "valorosos rapazes 
do club"; pelo contrário, permitir-se-ia que a Liga seguisse utilizando artifícios para neutralizar as agremiações do subúrbio, de forma que "suas injustiças (tomara que não se reproduzam - é sempre melhor) consigam as mesmas condescendências..." (VIDA..., 1918b, p. 3). Uma vez mais se percebe que o que estava em pauta extravasava os limites do futebol, tocando nas cisões da cidade.

O Bangú-Jornal em nenhum momento escondia a sua postura de defesa ao clube, assumindo textualmente a posição de "legítimo representante da região, obedecendo exclusivamente ao intuito de prestar-mos um relevante serviço aos nossos leitores" (VIDA..., 1918a, p. 3). Vejamos outro exemplo de críticas aos moldes do futebol então praticado e dirigido pelas elites.

Após uma vitória do Bangu sobre o Flamengo, por 4 a 2, na seção "Vida Sportiva" ironiza-se a agressão cometida por um player rubro-negro que, durante a partida, atingiu com bofetadas um jogador da equipe suburbana. Lembrando que tal fato foi fartamente discutido por outros periódicos, o cronista afirma que não poderia deixar passar em branco o ocorrido:

Os jornais diários já comentaram bastante os acontecimentos, mas nem por isso nos dispensamos de consignar nesta rápida nota os nossos mais energéticos protestos, patenteando o grande contraste que acaba de oferecer um club componente de operários, em sua absoluta maioria, com outro composto de gente fina! (VIDA..., 1918c, p. 3).

Propositalmente, o jornalista retoma e inverte uma discussão criada pela grande imprensa carioca: a falta de educação nos campos e a violência observável nos jogos. Ironicamente, observa que o mau comportamento foi tomado pelo Flamengo, um clube composto por "gente fina".

A vitória em uma situação de antagonismo social, exposto explicitamente pelo jornalista, uma agremiação de proletários e suburbanos versus outra que reunia jovens abastados, ganhava no Bangú-Jornal um tom de orgulho, uma espécie de satisfação com o próprio valor do suburbano. 
O cronista provoca ainda mais, dizendo-se sabedor de que esse procedimento inadequado do jogador rubro-negro "em nada poderá abonar os foros de boa reputação que até aqui tem sido o principal característica d'aquele club", já que as agremiações da zona sul contavam com a complacência dos cronistas da grande imprensa carioca (VIDA..., 1918c, p. 3).

Um dos que observou esse tratamento diferenciado por parte da imprensa foi Lima Barreto (1921, p. 5). O literato pôs em discussão uma notícia veiculada pelo jornal A Noite, em 13 de dezembro de 1920, na qual expôs um conflito entre as equipes do Mangueira e do Fluminense. Para o cronista, não era somente nos campos dos clubes de "terceira ordem" que tais cenas se verificam; as agremiações das elites "também se tem timbrado nesses desrespeitos à assistência, não atendendo sequer à presença de senhoras, que são atropeladas nas correrias e até agredidas, devido á confusão".

Para Lima Barreto (1921, p. 5), "trancos e pontapés" eram típicos do esporte. Por essa razão se perguntou: por quais motivos "clubs aristocratas e puros" seriam distintos dos "clubezinhos do subúrbio? O football é uma e mesma coisa em toda parte!".

Enfim, a grande imprensa representava de forma preconceituosa as agremiações da zona suburbana, um proceder que incomodava aqueles que lutavam pelos arrabaldes da cidade, que reagiram usando para tal as, ainda que modestas, armas que dispunham: a tinta e o papel.

\section{Conclusão}

Os jornais foram importantes agências na construção de representações sobre as agremiações do subúrbio. A grande imprensa as retratava de forma estereotipada, destacando sua suposta violência constante, considerada um desserviço prestado ao futebol. O mesmo procedimento, contudo, não era adotado com as agremiações da elite, comumente "perdoadas" pelos seus "deslizes" (SANTOS JUNIOR, MELO, 2013). 
Travava-se, na verdade, de uma noção preconceituosa de subúrbio, marcada por estigmas ligados à estratificação socioespacial da cidade. Era usual a desqualificação não só de torcedores e jogadores, como também dos bairros suburbanos como um todo. Essas ocorrências eram indícios dos conflitos que se estenderam por anos no futebol carioca, na mesma medida em que explicitavam a força da relação do esporte com os ethos em confronto.

Os periódicos suburbanos não ficaram inertes frente ao processo de estigmatização. A sua postura, diferentemente do que era anunciado nos discursos dos órgãos da grande imprensa, expressava sem delongas a ligação íntima com os clubes da região. Não só procuravam contestar o trato injusto e desigual para com o subúrbio, como também denunciar o que consideravam "artimanhas" das agremiações da elite para prejudicar o futebol local, entre as quais a contratação de jogadores. Se não tinham o mesmo poder dos jornais de grande circulação, sem dúvida gozavam de certa legitimidade, chegando mesmo a incomodar com seu comportamento "impertinente".

De toda forma, deve-se ter em conta que uma parte do processo que tentavam "combater", a transferência de players, seria mesmo irreversível. A profissionalização do futebol ainda iria desencadear muitas tensões e debates, mas depois preponderaria, contribuindo mesmo para um maior trânsito de diferentes estratos sociais no âmbito do velho esporte bretão.

Curiosamente, por vezes houve pontos em comum nas abordagens. Os dois grupos veicularam posições contrárias às transferências de jogadores, ainda que por razões distintas. Aliás, é curioso perceber como as críticas às ações do Vasco da Gama não vieram somente da grande imprensa. Os periódicos do subúrbio também em nada apreciaram a caça de players entabulada pelos cruzmaltinos. Prospectar tal posição permite contestar o mito de que esse clube foi o primeiro que se irmanou com o subúrbio.

Acreditamos que compreender melhor a consolidação do futebol no Rio de Janeiro deve significar também conhecer mais 
profundamente o que ocorria na zona suburbana, a partir de fontes que possam nos permitir o acesso ao cotidiano e aos pontos de vista dos líderes locais. Periódicos e atas dos clubes da região, por exemplo, podem trazer importantes pistas sobre as estratégias daqueles atores.

Esse tipo de abordagem, enfim, pode contribuir para tornar mais múltiplas e diversas nossas compreensões sobre o futebol brasileiro, que não foi somente uma obra das elites, mas sim uma construção em que também as periferias participaram ativamente. 


\section{"Recreation, instruction and defense of the suburban interests": points of view on football in the Gazeta Suburbana and the Bangú-Jornal (1918-1920)}

Abstract: This study aims to discuss some points of view on football published in two diaries of the Rio de Janeiro suburb: the Gazeta Suburbana and the BangúJornal. It was established as temporal cut the years 1918-1920 because it was a moment when increased tension in the football field of Rio de Janeiro, with a higher traffic of players among clubs of two important associations: Suburbana and Metropolitana. We suggest that this investigation can help broaden our eye on the sport because discuss the point of the view of leaders that tried to defense the interests of a pherypherical zone of the city.

Keywords: Football. Sport History. Press.

\section{"Recrear, instruir y defender los intereses suburbanos": posiciones sobre el fútbol en la Gazeta Suburbana y en el Bangú-Jornal (1918- 1920) \\ Resumo: Este estudio tiene el objetivo de analizar las posiciones sobre el fútbol en dos diarios del suburbio de Río de Janeiro: la Gazeta Suburbana e el Bangú- Jornal. Se estableció como corte temporal los años de 1918-1920, momento en que aumentó la tensión en el campo del fútbol en la ciudad, debido a un más grande tránsito de jugadores entre los clubes de dos importantes asociaciones: las Ligas Suburbana y Metropolitana. Consideramos que esta investigación puede ampliar nuestra visión sobre el deporte por tener en cuenta la mirada de los que defendían los intereses de una región periférica de la ciudad. \\ Palabras clave: Fútbol. História del Deporte. Prensa.}

\section{REFERÊNCIAS}

ABREU, M. A. A periferia de ontem: o processo de construção do espaço suburbano do Rio de Janeiro (1870-1930). Espaço e Debates, São Paulo, n. 21, p. 12-32, 1987.

NGU ATHLETIC CLUB. Livro de atas das sessões da diretoria. Rio de Janeiro, 1918. 
BARRETO, L. Uma conferencia esportiva. Careta, Rio de Janeiro, p. 5, 1 jan. 1921.

COM licença. Gazeta Suburbana, Rio de Janeiro, p. 1, 15 dez. 1883.

DIZEM... Gazeta Suburbana, Rio de Janeiro, p. 3, 5 abr. 1919.

ESTATUTOS da Liga Metropolitana de Desportes Terrestres. Diário Oficial da União, p. 13.577, 20 dez. 1917.

FOOT-BALL nos subúrbios. Gazeta de Notícias, Rio de Janeiro, p. 4, 13 abr. 1907.

LUCA, T. R. História do, no e por meio dos periódicos. In: PINSKY, Carla Bassanezi (Org.). Fontes históricas. São Paulo: Contexto, 2005. p. 111-53.

MALAIA, J. M. Revolução vascaína: a profissionalização do futebol e inserção sócio-econômica de negros e portugueses na cidade do Rio de Janeiro (19151934). 2010. 489f. Tese (Doutorado em História Econômica) - Departamento de História, Faculdade de Filosofia, Letras e Ciências Humanas da Universidade de São Paulo, São Paulo, 2010.

MELO, V. A. Causa e consequência: esporte e imprensa no Rio de Janeiro do século XIX e década inicial do século XX. In: HOLLANDA, B. B. B., MELO, V. A. (Org.). O esporte na imprensa e a imprensa esportiva no Brasil. Rio de Janeiro: 7 Letras, 2012. p. 21-51.

MELO, V. A e colaboradores. Pesquisa Histórica e História do Esporte. Rio de Janeiro: 7 Letras, 2013.

MENDONÇA, L. C. Nas margens: experiência de suburbanos com periodismo no Rio de Janeiro (1880-1920). 2011. 149f. Dissertação (Mestrado em História Social) - Instituto de Ciências Humanas e Filosofia, Departamento de História, Universidade Federal Fluminense, Niterói, 2011.

NOSSO rumo. Gazeta Suburbana, Rio de Janeiro, p. 1, 8 set. 1910.

PELO sem fio. Gazeta Suburbana, Rio de Janeiro, p. 3, 5 de abril de 1919.

PEREIRA, L. A. M. Footballmania: uma história social no Futebol do Rio de Janeiro: 1902-1938. Rio de Janeiro: Nova Fronteira, 2000.

POLLO, M. O incidente que provocou a invasão de campo. Correio da Manhã, Rio de Janeiro, p. 3, 23 out. 1916.

OS QUE desertam... Gazeta Suburbana, Rio de Janeiro, p. 3, 5 abr. 1919.

A REUNIÃO de hontem. Correio Da Manhã, Rio de Janeiro, p. 5, 17 jul. 1918.

SANTANA, W. P. As mãos negras do chauffeur Nelson da Conceição: futebol e racismo na cidade do Rio de Janeiro (1919-1924). 2013. 120f. Memória (Bacharelado em História) - Instituto de História, Universidade Federal do Rio de Janeiro, Rio de Janeiro, 2013. 
SANTOS JUNIOR, N. J. A construção do sentimento local: o futebol nos arrabaldes de Andaraí e Bangu (1914-1923). 2012. 126f. Dissertação (Mestrado em História Comparada) - Instituto de História, Universidade Federal do Rio de Janeiro, Rio de Janeiro, 2012.

SANTOS JUNIOR, N. J., MELO, V. A. Violentos e desordeiros: representações de dois clubes do subúrbio na imprensa carioca (década de 1910). Revista Brasileira de Educação Física e Esporte, São Paulo, v. 27, n. 3, p. 411-422, 2013.

A SUBURBANA é no futuro campeonato o celeiro da metropolitana. O Imparcial, Rio de Janeiro, p. 9, 22 mar. 1919.

O TÓPICO do "Bangú-Jornal". A Época, Rio de Janeiro, p. 9, 18 jul. 1918.

VIDA Sportiva. Bangú-Jornal, Rio de Janeiro, p. 3, 14 jul. 1918a.

VIDA Sportiva. Bangú-Jornal, Rio de Janeiro, p. 3, 21 jul. 1918b.

VIDA Sportiva. Bangú-Jornal, Rio de Janeiro, p. 3, 1 set. 1918c.

Endereço para correspondência:

Programa de Pós-graduação em História Comparada Instituto de História/Universidade

Federal do Rio de Janeiro. Largo de São Francisco, 1, sala 311 (secretaria)

200051-070 - Rio de Janeiro - RJ - Brasil

Aprovado em: 27.09.2013

Aprovado em: 11.12.2013

Movimento, Porto Alegre, v. 20, n. 01, p. 193-213, jan/mar de 2014 